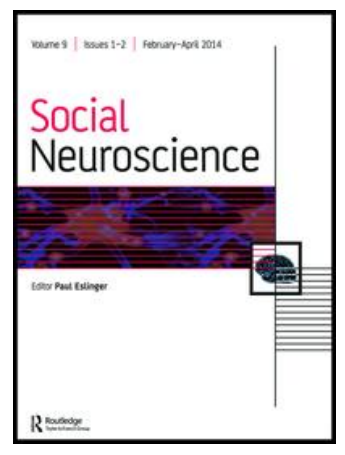

Social Neuroscience

ISSN: (Print) (Online) Journal homepage: https://www.tandfonline.com/loi/psns20

\title{
Exploring How Harming and Helping Behaviours Drive Prediction and Explanation During Anthropomorphism
}

\section{Lasana T. Harris, Noor van Etten \& Tamara Gimenez-Fernandez}

To cite this article: Lasana T. Harris , Noor van Etten \& Tamara Gimenez-Fernandez (2020):

Exploring How Harming and Helping Behaviours Drive Prediction and Explanation During Anthropomorphism, Social Neuroscience, DOI: 10.1080/17470919.2020.1799859

To link to this article: https://doi.org/10.1080/17470919.2020.1799859

Accepted author version posted online: 22 Jul 2020.

Submit your article to this journal 2

山 Article views: 2

Q View related articles

View Crossmark data $־$ 
Publisher: Taylor \& Francis \& Informa UK Limited, trading as Taylor \& Francis Group

Journal: Social Neuroscience

DOI: $10.1080 / 17470919.2020 .1799859$

Running Head: VALENCE AND ANTHROPOMORPHISM

Exploring How Harming and Helping Behaviours Drive Prediction and Explanation During Anthropomorphism

Lasana T. Harris ${ }^{1}$, Noor van Etten ${ }^{2}, \&$ Tamara Gimenez-Fernandez ${ }^{3}$

${ }^{1}$ Department of Experimental Psychology, University College London; ${ }^{2}$ Department of Social and Organizational Psychology, Leiden University; ${ }^{3}$ Department of Experimental Psychology, Autonomous University of Madrid lasana.harris@ucl.ac.uk 


\begin{abstract}
Cacioppo and colleagues advanced the study of anthropomorphism by positing three motives that moderated the occurrence of this phenomenon; belonging, effectance, and explanation. Here, we further this literature by exploring the extent to which the valence of a target's behaviour influences its anthropomorphism when perceivers attempt to explain and predict that target's behaviour, and the involvement of brain regions associated with explanation and prediction in such anthropomorphism. In a conceptual replication of the classic Heider and Simmel (1944) paradigm, participants viewed videos of geometric shapes, computer generated (CG) faces, and greebles in non-random motion performing harming and helping behaviours. Across two studies, participants reported a narrative that explained the observed behaviour (both studies) while we recorded brain activity (study one), and participants predicted future behaviour of the protagonist shapes (study two). Brain regions implicated in prediction error (striatum), not language generation (inferior frontal gyrus; IFG) engaged more to harming than helping behaviours during the anthropomorphism of such stimuli. Behaviourally, we found greater anthropomorphism in explanations of harming rather than helping behaviours, but the opposite pattern when participants predicted the agents' behaviour. Together, these studies build upon the anthropomorphism literature by exploring how the valence of behaviour drives explanation and prediction.
\end{abstract}

Keywords: anthropomorphism, social cognition, belonging, narrative, prediction, explanation 
Exploring How Harming and Helping Behaviours Drive Prediction and Explanation During Anthropomorphism

Anthropomorphism - engaging social cognition to non-human entities - demonstrates the pervasiveness of social perception, allowing human beings to imbue non-human entities with mental states (Epley, Akalis, Waytz, \& Cacioppo, 2008; Epley, Waytz, Akalis, \& Cacioppo, 2008; Epley, Waytz, \& Cacioppo, 2007). An agent — an entity that originates its own behaviour - that is not human can trigger anthropomorphism since people engage social cognition by default (Fiske \& Taylor, 1991; 2010). Such magical thinking satisfies the fundamental human motives to belong (Baumeister \& Leary, 1995), to make sense of or explain the world around us (Harris, 2017; Waytz, Morewedge, Epley, Monteleone, Gao, \& Cacioppo, 2010), and to exert a degree of control over our environment (Burger \& Cooper, 1979; Rothbaum, Weisz, \& Snyder, 1982; Rotter, 1966).

Concurrent with the rise of anthropomorphism research, social neuroscience emerged as a methodological tool to facilitate exploring the black box of social cognition (Harmon-Jones \& Devine, 2003; Ochsner \& Lieberman, 2001). After pioneering such psychophysiological techniques since the 1970's, Cacioppo advised that social psychological theory should play a central role in guiding brain imaging studies (Cacioppo, Berntson, Lorig, Norris, Rickett, \& Nusbaum, 2003). Here, we present research at the convergence of these two contributions, exploring how social psychology theory about social cognition during person perception can be applied to the study of anthropomorphism and the brain. Specifically, we examine the impact of the valence of the agents' behaviour on brain mechanisms implicated in explanation and prediction during anthropomorphism to provide converging evidence for behavioural data.

\section{Motives for Anthropomorphism}

Cacioppo and colleagues found evidence for three distinct motives for anthropomorphism; effectance, explanation, and belonging (Epley et al., 2007). Effectance motivation describes a perceiver's desire to have mastery over their environment (White, 1959). Therefore, 
anthropomorphism is more likely in cases where non-human agents do not function the way they are intended (Johnson \& Barrett, 2003; Waytz et al., 2010); by anthropomorphizing the agent, the perceiver retains control over the agent, attributing the dysfunction to the mind of the agent. Importantly, anthropomorphism in this instance also allows the perceiver to predict the future behaviour of the agent, further regaining control. This latter function of the effectance motive is implicit in the literature, but consistent with the function of social cognition in the person perception literature (see Andrews, 2005).

Also consistent with the person perception literature is the second motive for anthropomorphism: explanation. Imbuing an object with a mental life allows the perceiver to explain its behaviour because the agent's mental states are responsible for driving its behaviour (Dennett, 1989). This satisfies the fundamental human need for understanding (Baumeister \& Newman, 1994), providing reasons why the agent engaged in a particular behaviour. This social motive is also consistence with the effectance motive given that explanation and prediction are usually discussed as co-occurring during social cognition (see Fiske \& Taylor, 1991; 2010). However, the explanation motive stands apart since it is described usually as accessibility and applicability of explanations, rather than a strict focus of the engagement of explanatory processes for their own psychological benefit.

The final motive of belonging argues that a perceiver will see human beings in agents that are not human in a bid to form social connections when the perceiver is socially isolated (Eyssel \& Reich, 2013). This social motive to belong (Baumeister \& Leary, 1995) is consistent with hypersocial behaviour common amongst human beings (Hawkes, 2014; Hrdy, 2009; Tomasello \& Gonzalez-Cabrera, 2017; Tomasello, Melis, Tennie, Wyman, \& Herrmann, 2012). Thus, anthropomorphic perceptions should increase when the fundamental need to belong is threatened.

The three motives for anthropomorphism are a sub-set of a broader set of motives driving social cognition during person perception (for one account, see Fiske, 2003). In addition to 
effectance (control), belonging, and explanation (understanding), theorists argue that people engage social cognition to other people as a way of self-enhancing, and of trusting other people (Fiske, 2003). Self-enhancement is satisfied through impression management concerns (Kowalski \& Leary, 1990), and human beings have a fundamental need to trust other people (Bowlby, 1969). Both of these motives depend on the knowledge that a social target has a mind, and that said mind is capable of both forming an evaluation of the perceiver and of having good or bad intentions that would promote helping or harming behaviours towards the perceiver. Therefore, these latter two motives are irrelevant in the case of anthropomorphism if the perceiver preserves the belief that the non-human agent does not indeed actually have a mind, therefore is not forming an impression of the perceiver, and is not capable of harbouring good or ill intentions towards the perceiver. This belief keeps the anthropomorphised agent beyond the boundaries of moral protection, highlighting a fundamental difference between social cognition to human and non-human targets.

\section{Dissociating Social Cognition to People and Objects}

Engaging social cognition to people raises impression or reputation management concerns (Fiske \& Taylor, 1991; 2010) and makes morality salient (Bandura, 1989; Dennett, 1989). As mentioned above, anthropomorphism does not trigger such processing since people may preserve the belief that an anthropomorphised agent is not a human being. Therefore, it is useful to think about social cognition to agents on a continuum, with perception of full human beings at one end where morality and reputation concerns reside, and anthropomorphised agent perception at the other. Importantly, this continuum metaphor does not suggest that we consider anthropomorphism to be the opposite of full human perception. Stated differently, we did not put these two concepts on a continuum to posit them as opposites, but rather to suggest that though anthropomorphism is not the same as fully human perception, it is also not a discrete category. Therefore, our continuum is not a comprehensive continuum that describes the perception of all entities, including nonanthropomorphic simple objects. Rather, it is a continuum of social cognition (specifically mental 
state attribution or mind perception), with anthropomorphism anchoring one end, and fully human perception at the other.

At this point, it is also necessary to differentiate anthropomorphism from related psychological concepts. In the literature, researchers sometimes conflate the terms animacy, agency, and anthropomorphism. There are many living entities that are not animate (e.g. a tree), and there are many animate living entities that are not human (e.g. a squirrel). Therefore, all living entities are not animate, and an animate entity need not be alive. Nonetheless, animacy can be defined as the attribution of life to something. This is not the same as anthropomorphism, which describes attributing a mind (not a life) to a non-human entity. Our definition of anthropomorphism also differs from agency since agency is sufficient for anthropomorphism, but not necessary. For instance, a doll can be anthropomorphised even though it does not originate its own behaviour. Thus, though anthropomorphism and agency are terms often used interchangeably (Waytz et al., 2010), anthropomorphism goes beyond merely attributing life to an inanimate object or describing observable behaviour; the differences lies in qualities that people think of as distinctly human (possessing a mental life or mind). Perceivers use such a distinction to determine when agent perception results anthropomorphism (see Epley et al., 2008; Waytz et al., 2010). Moreover, although primary emotions like anger or happiness are not distinctly human, they are still part of the experience of being human (Demoulin, Leyens, Paladino, Rodriguez-Torres, Rodriguez-Perez, \& Dovidio, 2004).

Consistent with the distinction in motives driving social cognition to humans and nonhuman agents, separate but overlapping brain networks engage during social cognition to human and to non-human targets (Harris, Todorov \& Fiske, 2005; Harris \& Fiske. 2008). Specifically, areas of medial prefrontal cortex (MPFC), superior temporal sulcus (STS), temporo-parietal junction (TPJ), anterior temporal pole (ATP) precuneus, and posterior cingulate cortex (PCC) engage during social cognition (Amodio \& Frith, 2006; Frith \& Frith, 2002; Gallagher \& Frith, 
2002; Mars et al., 2012; van Overwalle, 2009). However, studies of anthropomorphism, while relying on the STS for biological motion detection (Puce \& Perrett, 2003; Servos, Osu, Santi, \& Kawato, 2002; Vaina, Solomon, Chowdhury, Sinha, \& Belliveau; 2001) and the perception of some objects such as greebles (Gautheir, Behrmann, \& Tarr, 2004), including the fusiform face area (Moran, Jolly, \& Mitchell, 2012; Schultz, Grelotti, Klin, Kleinman, Van der Gaag, Marois, et al., 2003), often depends on the amygdala (Harris \& Fiske, 2008; Heberlein \& Adoplhs, 2004) instead of MPFC, TPJ, and precuneus. Such dissociation may allow preservation of the belief that anthropomorphised agents are not human beings. However, such differences may also be due to the different visual complexity between geometric shapes and human beings, independent of morality.

\section{Explanation versus Prediction}

Explanation, effectance, and belonging overlap between social cognition to human and nonhumans. Explanation and prediction (effectance) in particular are relevant for social cognition to humans. Social psychological theory argues that the primary function of social cognition to humans is to explain and predict behaviour (Fiske \& Taylor, 1991; 2010). Specifically, knowing something about a person's mind makes salient their intentions, goals, emotional states, and personality traits; information that can be used to understand or explain why they engaged in past and current behaviour, and predict what behaviours they may engage in the future. Such mental state information not only satisfies the core human need for understanding, but also offers a degree of control over the perceiver's outcomes regarding that person. For instance, if Sally thinks that Anne harbours negative intentions towards her, Sally can adjust her behaviour and future interactions with Anne to minimise the likelihood that Anne can act on those ill intentions. Therefore, there are survival benefits related to engaging social cognition to any human being.

However, explanation and prediction are not opposite sides of the same coin. For instance, one might consider explanation as relying on inductive reasoning, while prediction depends on deductive reasoning. However, it is possible to make predictions without deductive reasoning 
(Andrews, 2009; 2012); infants without this advanced cognitive ability can still predict the behaviour of agents based on normative inferences (Phillips, Wellman, \& Spelke, 2002; Trevarthen, 1979). Moreover, studies with adults also question the role of social cognition in generating behavioural predictions. Personality traits are notoriously poor predictors of behaviour (Paunonen \& Jackson, 1985; Pervin, 1985), and at least one study that does not require trait generation demonstrates that norms better predict people's behaviour than traits (Harris, Lee, Thompson, \& Kranton, 2016). The question remains whether such distinctions between explanation and prediction are present during anthropomorphism.

\section{Valence of Behaviour}

There is a burgeoning literature on the valence of the behaviour of the anthropomorphic agent, and its impact on the extent to which the perceiver anthropomorphises the agent. For instance, agents who commit harms are attributed less agency than non-harmful agents (Khamitov, Rotman, \& Piazza, 2016). Agents that are harmed, however, are anthropomorphised more than nonharmed agents (Swiderska \& Kuster, 2018; Ward, Olsen, \& Wegner, 2013). Agents that are helped are also anthropomorphised more, but only when the perceiver takers the perspective of the helper (Tanibe, Hashimoto, \& Karasawa, 2017). However, in all these studies, the anthropomorphised agent was a robot, avatar, or corporation; a much more complex entity than simple geometric shapes.

The results above run counter to a negativity bias described in the person perception literature, such that harmful behaviours tend to better capture the attention, are better remembered, and lead to more dispositional attributions than helpful behaviours (Cacioppo \& Gardner, 1999; Carretie et al., 2001; Mogg \& Bradley, 1998; Mogg et al., 2000; Peeters \& Czapinsky, 1990; Taylor, 1991). In addition, negative events are more likely to be attributed to external sources, such as an anthropomorphized agent (Morewedge, 2009). Perhaps the difference between these two literatures hinges on the relevance of morality. If an agent is human, then that person's mind 
motivated their behaviour, and they can be held accountable for harmful behaviours; thus possessing a mind is necessary for such accountability. However, if an agent is not human, then moral rules need not apply, so thinking about their mind is superfluous. Given the low prevalence of witnessing geometric shapes compared to robots, avatars, and corporations as agents, agentic shapes engaged in harmful behaviours may be emotionally salient. Together, this literature suggests additional criteria may moderate anthropomorphism besides the three motives identified above, extending the work of Cacioppo and colleagues.

Here, we test the extent to which the valence of behaviour (harming versus helping) interacts with motives for anthropomorphism, specifically explanation and prediction. Specifically, in the first study, we explore brain mechanisms that underlie language generation (explanation) and decision-making (prediction) across harming and helping behaviours of different types of agents. We also vary the complexity of the agents to explore whether this variable interacts with valence. Hence, we aim to determine whether visual complexity (manipulated by the type of agent) or morality (manipulated by the valence of behaviour) contributed to differential processing in brain regions associated with prediction and explanation during anthropomorphism. In the second study, we focus on the anthropomorphism of geometric shapes, and explore the extent to which prediction and explanation are influenced by the motive to belong. In both studies, we hypothesise that there may be differential impacts of the valence of behaviour on explanation and prediction. Moreover, consistent with the literature, we hypothesise that feeling socially isolated may impact both explanation and prediction.

\section{Study One}

We constructed a brain imaging study to directly assess the impact of anthropomorphism on brain regions implicated in explanation and prediction. We conceptually replicated the classic Heider and Simmel (1944) paradigm of geometric shapes in non-random and random motion, adding two other agent categories with increased visual complexity as stimuli; greebles and 
computer-generated (CG) faces. These latter two agents matched the movement trajectories of the shapes, allowing us to determine whether the visual complexity of the agent mattered for both explanation and prediction. Greebles are objects that drive activity in the STS and fusiform gyrus (Puce \& Perrett, 2003; Servos, et al., 2002; Vaina, et al., 2001), providing us an agent that was more visually complex than a geometric shape, but not as complex as humans. CG faces are much closer to humans on the human-object spectrum, but are not actual humans' faces. Nonetheless, they are substantially more visually complex than both greebles and geometric shapes. We compare activity to these different agents performing helping and harming behaviours in a brain region associated with language generation (IFG) and one associated with prediction error (striatum). We expect that if certain agents or valenced behaviours drive more predictive or explanatory processes, we should detect differences in the respective brain regions.

\section{Method}

\section{Participants}

Twenty participants completed the brain imaging paradigm. We lost four participants to data recording errors, resulting in a final sample of 16 participants recruited from an American University population. All participants gave informed consent before beginning the experiment, and the study received ethical approval from the University Institutional Review Board.

\section{Materials}

We created 180 videos, varying the colours, families, or identities of the agents (geometric shapes, greebles, or CG faces) across two stimuli sets (see Figure 1). Each video lasted 20 seconds. The geometric shapes were circles, squares, and pentagons, and were either red, yellow, blue, purple, orange, or green. The greebles came from a database of such objects (see Gauthier \& Tarr, 1997), and equal numbers were selected from the same two 'families'. CG faces came from a face database (Oosterhof \& Todorov, 2008), and each face selected was at the midpoint of dominance and trustworthiness dimensions. Within each stimulus set, there were 30 videos for each agent 
category, 10 displaying helping behaviour, 10 displaying harmful behaviour, and 10 engaged in random motion. The videos depicted different kinds of behaviours, including agents trapped in structures, going up inclines and steps, sorting and arranging objects, or avoiding other agents. Each video contained two primary agents that both belonged to a category (geometric shapes, greebles, CG faces), except for the avoiding video where small dots served as the agents to be avoided in addition to the two primary agents. To manipulate the identities of the agents, we substituted the geometric shapes with either greebles or CG faces. Therefore, the movement pattern of the agents was identical across these three conditions. Harming and helping behaviours were differentiated by the goals of the agents, such that harming agents hindered the other agent with the task, while helping agents assisted.

\section{Procedure}

We counterbalanced the two stimuli sets across participants, such that half of the participants viewed videos from one set, and the other half of participants from the second set. Participants viewed 90 videos of agents, in random and non-random motion. Participants were instructed to tell stories silently in their heads about the action they observed in the videos. Each video was randomly presented, followed by a two to eight second jittered fixation cross. After scanning, participants observed the 20 shape videos displaying harming and helping behaviours, and wrote down the story they had told themselves in the scanner about the action. Participants were paid \$20 for their participation, fully debriefed, and thanked.

\section{fMRI Acquisition and Data Analysis}

We used a 3.0 Tesla GE Signa Excite head-dedicated scanner to collect structural images (T1-weighted MPRAGE: 256 x 256 matrix; FOV = $256 \mathrm{~mm} ; 116$ 1-mm sagittal slices) followed by functional images $\left(\mathrm{EPI}\right.$ sequence: $\mathrm{TR}=2000 \mathrm{~ms} ; \mathrm{TE}=25 \mathrm{~ms} ; \mathrm{FOV}=192 \mathrm{~cm}$; flip angle $=75^{\circ}$; echo spacing $=0.29 \mathrm{~ms} ; 39$ slices; voxel size: $3 \times 3 \times 3 \mathrm{~mm}^{3}$ ). A computer presented the stimuli 
projected to a screen mounted at the rear of the scanner bore. Stimuli were reflected through a filter and a mirror, which participants viewed while supine.

\section{BOLD Data Preprocessing}

Both image preprocessing and statistical analysis used Brain Voyager QX (http://www.brainvoyager.de). Before statistical analysis, image preprocessing consisted of: 1) slice acquisition order correction; 2) 3D rigid-body motion correction; 3) voxelwise linear detrending across time; 4) temporal bandpass filtering to remove low and high frequency (scanner and physiology related) noise. We corrected distortions of EPI images with a simple affine transformation. We registered functional images to the structural images and interpolated to cubic voxels. After coregistering participants' structural images to a standard image using a 12-parameter spatial transformation, we similarly transformed their functional data, along with a standard moderate degree of spatial smoothing (Gaussian $8 \mathrm{~mm}$ FWHM).

\section{BOLD Data Analysis Strategy}

Data analysis used the general linear model available on the Brain Voyager QX software package. We conducted a random-effects general linear model (GLM) analysis on blood oxygen level dependent (BOLD) signal with predictors during the video displays. We also added predictors for motion correction to the model. We convolved the predictors with a standard canonical hemodynamic response function. We transformed structural and functional data of each participant to standard Talairach stereotaxic space (Talairach \& Tournoux, 1988).

We first conducted region of interest (ROI) analyses on brain regions associated with explanation and prediction; we identified brain regions using the Neurosynth database by searching for the terms 'prediction' (bi-lateral putamen in the striatum: $x=(-) 14, y=10, z=-10$; see Figure 2a) and 'language network' (bi-lateral inferior frontal gyrus; BA 45: $x=(-) 47, y=24, z=16$ IFG). We then drew $10 \times 10 \times 10$ voxel cubes around the target voxel for each brain region, before extracting the average data for each of our predictors. We ran 3 agent $\mathrm{X} 3$ behaviour repeated 
measures analysis of variance (ANOVA) on each ROI. We followed up significant main effects and interactions with simple effect contrasts, Bonferroni corrected for multiple comparisons, $\alpha=2.78 \mathrm{E}-$ 3. We only reported below marginal or significant differences if the confidence intervals $(\mathrm{CI})$ for the simple effect contrast did not include zero.

We then performed whole brain contrasts on the data, focusing on harming versus helping behaviour, non-random versus random motion, and deviant cell contrasts for each of the three agents (we reported these results in Tables 1 - 5). In addition, we performed a weighted analysis such that we computed the average number of mental state words (e.g. want) and human words (e.g. friend) across all participants independently for each type of behaviour (see Table 6 for means) from the participants' narratives post-scanning. We then used these means as weights for each type of behaviour during a whole brain GLM ANOVA of the brain data, independently for each type of agent, and collapsed across agents. Because of the low prevalence of human word use (all means below 1), we only ran this analysis for mental state words usage (we report these results in Tables 7 $-10)$.

\section{Results and Discussion}

\section{Striatum ROIs}

We computed a 3 agent (CG face, greeble, shape) X 3 behaviour (helping, harming, random) ANOVA on the left striatum ROI. We did not find significant agent or behaviour main effects, but we did find a significant agent $\mathrm{X}$ behaviour interaction, $F(4,60)=4.45, p=.003$, partial $\eta^{2}=0.23, \Omega=0.92$ (see Figure $2 \mathrm{c}$ ).

For CG faces, we found a marginal difference between harming and helping behaviour, $t$ $(15)=2.51, p=.024,95 \%$ CIs [0.03, 0.41], such that harming behaviour engaged the brain region more than helping behaviour. There were no differences between harming or helping behaviour and random behaviour. However, greebles showed a marginal difference between harming and random behaviour, $t(15)=2.23, p=.042,95 \%$ CIs [0.01, 0.31], with more brain activity for harming 
relative to random behaviour. There was no such difference between helping and random behaviour, but we did find marginally more engagement during harming compared to helping behaviour, $t(15)=2.34, p=.034,95 \%$ CIs $[0.02,0.44]$. However, shapes only showed a marginal difference between harming and random behaviour, $t(15)=1.92, p=.027,95 \%$ CIs [0.04, 0.48], with more brain activity to random rather than harming behaviour. No other difference was significant for shapes.

For harming behaviour, CG faces engaged the region marginally more than geometric shapes, $t(15)=2.59, p=.021,95 \%$ CIs $[0.05,0.51]$, and greebles engaged more than geometric shapes, $t(15)=3.58, p=.003,95 \%$ CIs $[0.09,0.58]$, but CG faces and greebles did not differ on harming behaviour. None of the agents differed for helping behaviour, or for random motion.

We found very similar effects in the right striatum. We did not find a significant agent main effect, but we did find a marginally significant behaviour main effect, $F(2,30)=2.75, p=.080$, partial $\eta^{2}=0.16, \Omega=0.51$. This main effect was qualified by a significant agent $\mathrm{X}$ behaviour interaction, $F(4,60)=3.66, p=.010$, partial $\eta^{2}=0.20, \Omega=0.85$ (see Figure $2 b$ ). For CG faces, there was a marginal difference between harming and random behaviour, $t(15)=2.55, p=.022$, $95 \%$ CIs $[0.02,0.26]$, such that harming behaviour engaged the brain region more than random motion. We found no such difference between helping behaviour and random motion, or between harming and helping behaviour. Greebles showed a similar pattern to faces; a marginal difference between harming and random behaviour, $t(15)=2.83, p=.013,95 \%$ CIs $[0.05,0.35]$, with more brain activity for harming relative to random behaviour. However, there was marginally more engagement during harming compared to helping behaviour, $t(15)=2.99, p=.009,95 \% \mathrm{CIs}[0.06$, 0.39]. Finally, geometric shapes only showed a marginal difference between harming and random behaviour, $t(15)=2.43, p=.028,95 \%$ CIs $[0.02,0.34]$, with more brain activity to random rather than harming behaviour. 
For harming behaviour, greebles engaged more than geometric shapes, $t(15)=3.51, p=$ $.003,95 \%$ CIs $[0.11,0.45]$, but CG faces and greebles did not differ on harming behaviour, nor did CG faces and geometric shapes differ. None of the agents differed for helping behaviour, or for random motion.

Together, the pattern of results for brain regions implicated in prediction suggest valence of behaviour and agent complexity mattered. Specifically, harming behaviours from more visually complex agents engaged these regions more than helping behaviours or random motion from less visual complex agents.

\section{IFG ROIs}

We computed a 3 agent (CG face, greeble, geometric shape) X 3 behaviour (helping, harming, random) ANOVA on the left IFG ROI. We did not find any significant main effects or interactions. We computed a similar analysis on right IFG, and also found no significant main effects or interactions. This suggests that a brain region implicated in language generation did not differentiate valence of behaviour or type of agent in our paradigm.

\section{Study Two}

The first study provided partial support for the notion that harming behaviours drove brain mechanisms implicated in prediction during anthropomorphism more than helping behaviours. We did not find a similar effect for brain regions implicated in language production, which is associated with explanation. However, there are a number of limitations with the first study that affect the causal inferences that can be drawn from the data. Firstly, we relied on ROI analyses of a relatively small area of cortex, when activation patterns for both constructs typically engage more than the limited number of voxels we explored. Secondly, the search terms 'prediction' and 'language network' are analogues of the kinds of processes we expect to be active during anthropomorphism, not necessarily the specific processes themselves. Thirdly, the repeated measures design meant that participants saw the different types of agents performing exactly the same actions with different 
intentions (harming versus helping), which could have led to spill-over effects from one agent to another, and from one valence to the other. Finally, the effects and sample sizes are rather small.

In the second study, we attempted to replicate the finding that the valence of behaviour influenced the extent to which participants would explain and predict the anthropomorphic agent's behaviour in an online study. We used only videos of geometric shapes in non-random motion in a conservative attempt to replicate the previous effects, ignoring agent complexity. Moreover, we explicitly assessed both explanation and prediction rather than simply relying on reverse inferences from brain activity. Specifically, participants explained the current behaviour of the main protagonist shape by telling a narrative that fit the behaviour, and predicted the behaviour of the protagonist shape in future shape-to-shape interactions that were either relevant or irrelevant to the observed behaviour. We included the relevant and irrelevant behaviour during the prediction task to add precision to our prediction measure. Specifically, participants should predict from past behaviour only for relevant behaviour; prediction to irrelevant behaviour suggest a process separate from prediction (the observed behaviour does not inform the irrelevant prediction) such as generalisation or some other psychological construct. Thus, the irrelevant behaviour condition served as a control to allow us to better interpret the prediction results. Finally, given the central role of belonging as a motive for anthropomorphism, we manipulated the extent to which participants believed their future would be filled with social relationships or isolation to assess the impact of this motive on explanation and prediction.

\section{Method}

\section{Participants}

Ninety-two participants participated in the study, (27 males, 65 females), ranging in age from 16 to $42(\mathrm{M}=21.86, \mathrm{SD}=3.18)$. The majority of participants were Dutch natives at University $(\mathrm{n}=85)$ and had attained a high educational level $(\mathrm{n}=61$ graduates on VWO-level, $\mathrm{n}=$ 22 university bachelor or master graduates, $\mathrm{n}=9$ graduates on havo- or HBO-level). All 
participants who began the completed it, thus there was no attrition or exclusion of participants. The study received ethical approval from the Psychology Department's Ethical Review Board.

\section{Measures}

We programmed the experiment using Qualtrics. To account for the participants' need for belonging prior to the experiment, we used the Need to Belong Scale; a ten item measure about the individual's urge for belonging, including items like: "I do not like being alone" and "My feelings are easily hurt when I feel that others do not accept me" (Leary, Kelly, Cottrell, \& Schreindorfer, 2003). We found no differences on this measure and do not discuss it further.

Moreover, we used the first thirty items of the Eysenck Personality Questionnaire translated in Dutch (Sanderman, Arrindell, \& Ranchor, 1991) to manipulate loneliness. Participants either agreed or disagreed to several personality-related questions. For the manipulation check, participants rated their feelings on six emotions (sad, happy, lonely, at ease, tense, and satisfied) on a five-point scale $(1=$ absolutely disagree through $5=$ absolutely agree $)$.

Finally, participants had to make a prediction about the future behaviour of the geometric shapes by answering eight questions immediately following each video. Four questions asked about helping behaviour showed in the videos: the likelihood of the geometric shape helping the other shape to clear items away, climb a staircase, escape a closed space, and sorting elements in the future. The exact same questions addressed harming behaviours by asking about the likelihood of one geometric shape preventing another geometric shape from carrying out these four actions. Participants answered these questions on a five-point scale $(1=$ highly unlikely through $5=$ highly likely) each time after viewing a movie.

\section{Procedure}

We recruited participants using a snow-ball technique by putting advertisements on social media platforms. We did not inform participants of the true nature of the experiment, but told them that it was about the individual perceptions of certain geometric shapes. The only selection criteria 
were that participants must be Dutch-speakers and 18 years of age or older. Once participants contacted the experimenter, we sent them an internet link to participate in the study. Participants were asked to read the instructions carefully and eliminate distractions. Participation took place anonymously and on a voluntary basis. As a reward, participants received $€ 3$. The experiment took approximately thirty minutes.

First, participants reported their demographic information: gender, age, nationality, religious background, and educational level. Next, we asked them to answer all questions as honestly as possible without thinking too long about their answers. They were told that they had to fill out a questionnaire about their personality before viewing videos involving geometrical shapes in motion. We used no anthropomorphic terms to describe what would be showed to prevent participants from starting to anthropomorphise before they had seen any of the videos.

Subsequently, we manipulated loneliness using an approach in the literature (Twenge, Baumeister, Tice, \& Stucke, 2001). Specifically, we asked participants to complete the Eysenck Personality Questionnaire. When finished, we told participants that their results were being processed and would add up to a short personality description. We then randomly assigned participants to one of our two between-subject conditions. In the experimental condition, participants read that their personality type was an indicator of becoming lonely later in life, specifically we told them: "You are the type of person who ends up lonely later in life. Even though you have friends and relationships now, they are not likely to hold in the future. Chances are that you will end up being alone more and more." In the control condition, we told participants that they would end up having lots of successful relationships and never be lonely, specifically: "You are the type of person who has rewarding relationships throughout life. The friends and relationships that you have now are likely to hold in the future. Chances are that you will always have friends and people around who care about you." The loneliness manipulation was immediately followed by the manipulation check. 
We then showed participants fifteen short videos of moving geometrical shapes; 5 each displaying harming, helping, and random behaviours. The videos always involved two shapes at the time. A square was present in every single video. The other two shapes were a circle always engaging in "helping" behaviour and a pentagon always portraying "harming" behaviour. In the random videos, the presence of either the pentagon or the circle was varied. The videos also showed inanimate objects used by the shapes, like a staircase or triangles that were put away in a box. The helping behaviour consisted of the circle helping the square escape from a closed box, helping escape from a closed circle, sorting objects, packing objects away, and climbing a staircase. The harming behaviour entailed the pentagon disallowing the square to perform these actions. In the random videos, both geometric shapes moved around the screen in a random motion. All participants described as accurately as possible what they had witnessed immediately after viewing each of the fifteen videos in a blank box on the screen without a time limit. Participants then made predictions about the behaviour of the geometric shapes by answering questions: "How likely is this shape to help another shape to escape a trap?; How likely is this shape to help another shape climb a staircase?; How likely is this shape to help another shape put objects away?; How likely is this shape to help another shape sort objects?" We also asked questions about harming behaviour where we replaced the phrase "to help" with "to prevent" in the four questions above. Finally, participants filled out the Need to Belong Scale. We then debriefed participants and solicited information for payment.

\section{Data Analysis Strategy}

We computed two valenced scales for the manipulation check questions, averaging the three positive emotions (happy, at ease, satisfied) and the three negative emotions (sad, lonely, tense). We then conducted reliability analysis for both scales, revealing good reliability for the positive (Cronbach's $\alpha=0.88$ ) and negative scales (Cronbach's $\alpha=0.79$ ). 
We defined words as anthropomorphic if they consisted of attributing personality traits or a humanlike mind to the shapes such as emotions, intentions, and conscious awareness. We did not count words as anthropomorphic if they only described the shapes in terms of being alive and able to move by themselves. We counted both primary and secondary emotions as anthropomorphic. We also included verbs related to human actions (e.g. celebrating, giving a high five, crying when hindered), mental state verbs (e.g. wish, want, hope) or the inference of a human relationship between shapes (e.g. siblings, friends, enemies, or parent and child). We counted the number of anthropomorphic inferences in the text descriptions by listing all such verbs and nouns. If participants used the same word more than once, it was counted individually each time. We divided all words into two groups: anthropomorphic and non-anthropomorphic. We computed an anthropomorphic ratio for helping, harming, and random behaviour by dividing the number of anthropomorphic words for a particular behaviour by the total number of words (anthropomorphic and non-anthropomorphic). We then ran an ANOVA on these ratios, and followed up significant main effects and interactions with simple effect contrasts, Bonferroni corrected for multiple comparisons with an $\alpha=8.33 \mathrm{E}-2$. To provide further evidence for the anthropomorphism of the geometric shapes, we submitted the ratios, collapsed across the isolation conditions, to a one-sample $t$-test against zero, Bonferroni corrected for multiple comparisons with an $\alpha=1.67 \mathrm{E}-2$.

We computed dependent variables for relevant and irrelevant prediction behaviour by averaging across the appropriate questions across the videos. This resulted in averaged responses to questions about predicted valenced behaviour (helping or harming) that was either relevant or irrelevant to the geometrics shape behaviour depicted in the video after observing helping or harming shape behaviours. We then ran an ANOVA on these prediction likelihood ratings, and followed up significant main effects and interactions with simple effect contrasts, Bonferroni corrected for multiple comparisons with an $\alpha=2.08 \mathrm{E}-3$. We excluded the random videos from this analysis since there was no relevant behaviour. 


\section{Results and Discussion}

\section{Manipulation Check}

The loneliness manipulation significantly influenced responses on the positive affect (Levene's test for Equality of Variances significant, $F=21.92, p=1.00 \mathrm{E}-05$, therefore, corrected statistics) $t(70.14)=-4.17, p=8.60 \mathrm{E}-05,95 \% \mathrm{CI}[-1.18,-0.42]$; participants in the control condition reported significantly higher positive emotions $(M=4.06, S D=0.67)$ than participants in the lonely condition $(M=3.26, S D=1.09)$. However, the manipulation only marginally influenced negative affect, $t(90)=1.78, p=.078,95 \%$ CI $[-0.05,0.84]$; participants in the lonely condition $(M$ $=2.58, S D=1.15)$ reported feeling slightly more negative emotions than participants in the control condition $(M=2.18, S D=0.98)$. Therefore, we concluded that the manipulation was partially effective.

\section{Explanations}

We ran a 2 isolation (lonely, not lonely) X 3 word type (helping ratio, harming ratio, random ratio) mixed ANOVA on word usage to determine differences in the amount of anthropomorphism in the explanation of the behaviour of the shapes. We found a significant main effect of word type, $F(2,180)=142.70, p=7.43 \mathrm{E}-38$, partial $\eta^{2}=0.61, \Omega=1.00$ (see Figure 3$)$. We found a significant difference between helping ratio and harming ratio, $t(91)=4.33, p=3.10 \mathrm{E}-5,95 \%$ CIs $[0.01,0.03]$, such that the harming ratio was greater than the helping ratio $\left(M_{\text {diff }}=0.02, S D_{\text {diff }}=\right.$ 0.04). This suggests participants anthropomorphised harming behaviour more than helping behaviour. We also found significant differences between both the harming ratio and the random ratio, and the helping ratio and the random ratio, respectively $t(91)=14.89, p=3.99 \mathrm{E}-26,95 \% \mathrm{CIs}$ $[0.06,0.07]$, such that the harming ratio was greater than the random ratio, $\left(M_{\text {diff }}=0.07, S D_{\text {diff }}=\right.$ $0.04)$, and $t(91)=15.04, p=2.04 \mathrm{E}-26,95 \% \mathrm{CIs}[0.04,0.05]$, such that the helping ratio was greater than the random ratio, $\left(M_{\text {diff }}=0.05, S D_{\text {diff }}=0.03\right)$. Together, these results suggest that participants did anthropomorphize harming and helping behaviour more than random movement, but 
anthropomorphized harming behaviour the most, consistent with study one and our hypotheses. Moreover, the isolation main effect was not significant, $F(1,90)=0.01, p=.939$, and it did not interact with the word type main effect, $F(2,180)=0.15, p=.853$. This suggests that feeling isolated or not did not affect the extent to which participants anthropomorphised the movement of the geometric shapes.

For tests against zero, we found that only the harming ratio, $t(91)=15.00, p=2.87 \mathrm{E}-26$, $95 \%$ CIs $[0.06,0.08]$, and helping ratio, $t(91)=15.78, p=8.72 \mathrm{E}-28,95 \%$ CIs $[0.04,0.05]$, were significantly different from zero, while the random ratio was not, $t(91)=1.92, p=.059,95 \%$ CIs [3.0E-5, 1.6E-3]. This suggests that participants only anthropomorphised during helping and harming, but not random movement of the geometric shapes.

Together, these results support the notion that harming behaviour generates more anthropomorphism, than helping behaviour, though both types of behaviour generated anthropomorphism. However, since the word generation is also a measure of explanation, we can also conclude that harming behaviour increased the motive to explain the behaviour.

\section{Predictions}

We ran a 2 predicted behaviour (helping, harming) X 2 relevance of the question to the depicted shape behaviour (relevant, irrelevant) X 2 observed shape behaviour (helping harming) X 2 isolation (lonely, not lonely) mixed ANOVA on behavioural predictions. We found a significant main effect of observed shape behaviour, $F(1,90)=9.49, p=.003$, partial $\eta^{2}=0.10, \Omega=0.86$, such that predictions based on observing helping behaviours $(M=2.68, S D=0.71)$ were rated as more likely than predictions based on observing harming behaviours $(M=2.62, S D=0.60)$. We found a main effect of relevance, $F(1,90)=75.16, p=1.67 \mathrm{E}-13$, partial $\eta^{2}=0.46, \Omega=1.00$, such that responses to questions relevant to the depicted behaviour $(M=3.00, S D=0.72)$ were higher than responses to questions irrelevant to the predicted behaviour $(M=2.34, S D=0.97)$. We found a main effect of predicted behaviour, $F(1,90)=7.52, p=.007$, partial $\eta^{2}=0.08, \Omega=0.77$, such that 
future helping behaviour $(M=2.69, S D=0.69)$ was predicted as more likely than future harming behaviour $(M=2.61, S D=0.72)$. These main effects were qualified by significant two-way interactions, specifically observed shape behaviour $\mathrm{X}$ relevance, $F(1,90)=39.53, p=1.13 \mathrm{E}-8$, partial $\eta^{2}=0.31, \Omega=1.00$, observed shape behaviour X predicted behaviour, $F(1,90)=757.39, p$ $=1.33 \mathrm{E}-45$, partial $\eta^{2}=0.89, \Omega=1.00$, and relevance X predicted behaviour, $F(1,90)=46.48, p$ $=1.03 \mathrm{E}-9$, partial $\eta^{2}=0.34, \Omega=1.00$. All two-way interactions and main effects were qualified by a significant three-way interaction between predicted behaviour, relevance, and observed shape behaviour, $F(1,90)=265.17, p=1.43 \mathrm{E}-28$, partial $\eta^{2}=0.74, \Omega=1.00$ (see Figure 4).

To unpack the interaction, we first consider simple effects separately for relevant and irrelevant behaviour. For relevant behaviour, observed helping behaviour led to significantly more predicted helping rather than predicted harming behaviour, $t(91)=45.31, p=3.12 \mathrm{E}-64,95 \% \mathrm{CIs}$ [3.37, 3.68], and observed harming behaviour led to significantly more predicted harming rather than predicted helping behaviour, $t(91)=37.90, p=1.58 \mathrm{E}-57,95 \%$ CIs [2.96, 3.29]. We found a similar pattern for the irrelevant behaviour, such that observing helping behaviour led to significantly more predicted helping rather than predicted harming behaviour, $t(91)=9.36, p=$ 5.47E-15, 95\% CIs $[1.01,1.56]$, and observing harming behaviour led to significantly more predicted harming rather than predicted helping behaviour, $t(91)=11.05, p=1.68 \mathrm{E}-18,95 \% \mathrm{CIs}$ $[1.14,1.64]$.

A similar pattern emerged when we consider simple effects based on the predicted behaviour. When predicting future helping behaviour, observing relevant helping rather than harming behaviour led to increased predictions, $t(91)=48.17, p=1.48 \mathrm{E}-66,95 \%$ CIs $[3.34,3.63]$. A similar effect emerged for observing irrelevant helping rather than harming behaviour, $t(91)=$ 9.85, $p=5.23 \mathrm{E}-16,95 \%$ CIs $[1.04,1.56]$. Similarly, when predicting future harming behaviour, observing harming rather than helping behaviour led to increased predictions, $t(91)=37.43, p=$ 
4.60E-57, 95\% CIs [2.99, 3.33], as did predicting irrelevant harming rather than helping behaviour, $t(91)=10.86, p=4.11 \mathrm{E}-18,95 \%$ CIs $[1.12,1.62]$.

However, the pattern was different when we considered simple effects separately for observing helping and harming behaviour. When participants observed helping behaviour, predicting relevant helping behaviours was more likely than predicting irrelevant helping behaviours, $t(91)=13.39, p=3.20 \mathrm{E}-23,95 \%$ CIs $[1.56,2.11]$. However, predicting relevant harming behaviours was less likely than predicting irrelevant harming behaviours, $t(91)=-6.40, p$ $=6.64 \mathrm{E}-09,95 \%$ CIs $[-0.53,-0.28]$. We again saw a similar pattern when participants observed harming behaviours, such that predicting relevant harming behaviours was more likely than predicting irrelevant harming behaviours, $t(91)=12.84, p=3.93 \mathrm{E}-22,95 \%$ CIs $[1.17,1.60]$. However, predicting relevant helping behaviours was less likely than predicting irrelevant helping behaviours, $t(91)=-6.54, p=3.54 \mathrm{E}-09,95 \%$ CIs $[-0.46,-0.25]$.

The isolation main effect was not significant, $F(1,90)=2.47, p=.120$. We did however find a marginally significant isolation $\mathrm{X}$ observed shape behaviour interaction, $F(1,90)=3.51, p=$ .064 , partial $\eta^{2}=0.04, \Omega=0.46$, and a marginally significant isolation X relevance interaction, $F$ $(1,90)=2.78, p=.099$, partial $\eta^{2}=0.03, \Omega=0.38$. These were qualified by a significant isolation $\mathrm{X}$ observed shape behaviour $\mathrm{X}$ relevance three-way interaction, $F(1,90)=6.04, p=.016$, partial $\eta^{2}=0.06, \Omega=0.68$ (see Figure 5). No other interactions were significant.

To unpack this interaction, we consider simple effect contrasts separately for the lonely and not lonely conditions. For the lonely condition, we found that observing relevant helping rather than relevant harming behaviour did not lead to increased predictions, $t(43)=2.74, p=.009,95 \%$ CIs $[0.02,0.15]$. A similar lack of a significant effect emerged for observing irrelevant helping rather than irrelevant harming behaviour, $t(43)=-1.49, p=.145,95 \%$ CIs $[-0.09,0.01]$. However, we found a different pattern for these contrasts in the not lonely condition, such that observing relevant helping rather than harming behaviour did lead to increased predictions, $t(47)=5.07, p=7.00 \mathrm{E}-6$, 
95\% CIs [0.14, 0.33], but observing irrelevant helping rather than harming behaviour did not lead to a significant difference in predictions, $t(47)=-1.13, p=.263,95 \%$ CIs [-0.11, 0.03].

When examining simple effects within observed shape behaviour, for the lonely condition, we found that observing relevant rather than irrelevant helping behaviour led to increased predictions, $t(43)=5.29, p=4.00 \mathrm{E}-6,95 \%$ CIs $[0.34,0.77]$, as did observing relevant rather than irrelevant harming behaviour, $t(43)=4.92, p=1.30 \mathrm{E}-5,95 \%$ CIs [0.26, 0.61]. A similar pattern emerged in the not lonely condition, such that observing relevant rather than irrelevant helping behaviour led to increased predictions, $t(47)=7.34, p=2.54 \mathrm{E}-9,95 \%$ CIs $[0.63,1.10]$, as did observing relevant rather than irrelevant harming behaviour, $t(47)=6.39, p=6.96 \mathrm{E}-8,95 \%$ CIs $[0.40,0.78]$. We found no further simple effect contrast differences.

Unlike the results for the explanation dependent variable, the prediction dependent variable shows more prediction of the helping behaviour rather than the harming behaviour. When taken together with the explanation results, these data suggest that the presence of one motive reduces the influence another motive. Specifically, when participants generated explanations, satisfying the motive to understand, the negativity bias remained. Moreover, we observed an interesting dissociation in the valence of behaviour, such that participants explained harming behaviour more, but predicted helping behaviour more. Perhaps in the case of understanding, negative behaviour perhaps loomed larger, while in the case of predicting, positive behaviour seemed more reliable. Further research is necessary to further parse such effects. 


\section{General Discussion}

Across two studies, we demonstrate a difference in the valence of behaviour, and between prediction and explanation, during anthropomorphism. Specifically, we find that harming behaviours led to more explanation, while both harming and helping behaviour led to more predictions about the future behaviour of the anthropomorphised agents. Moreover, we found evidence that brain regions engaged in prediction were sensitive to differences in the visual complexity of the anthropomorphised agents, engaging more to visually complex objects. In addition, the findings of the whole brain contrasts are consistent with the literature, such that greebles and CG faces engage parts of the temporal lobe. Together, these findings further the literature on the motives of anthropomorphism, finding support for the role of effectance, understanding, and belonging motives while also highlighting the impact of visual complexity of the agent and valence of behaviour.

\section{Limitations}

However, there are a number of limitations with the current pair of studies. Firstly, our measures of explanation double as our measure of anthropomorphism. Therefore, it is not possible to separate this motives for anthropomorphism from actual anthropomorphism. We decided not to explicitly ask participants to make ratings of the extent to which they perceived a mind in the agents in an attempt not to bias them into anthropomorphising the observed motion. But the question remains whether dissociating the explanation motive from independently measured anthropomorphism would have led to different results.

Secondly, our sample size for the brain imaging study is small, and our ROIs not ideal. Regarding the ROIs, we randomly selected voxels from big swaths of the brain depicted as active for each of our key terms in the Neurosynth software. This approach allowed us unbiased ROIs, but the possibility exists that other ROIs centered around other locations in the database may have shown a different pattern. We cannot rule out such limitations, and do not test additional ROIs 
because of the concern surrounding multiple comparisons. However, future studies could independently define the ROIs using localiser tasks with a larger sample, reducing this limitation.

Next, our selection of brain regions, though guided by Neurosynth, still relied on reverse inferences. For instance, though studies of silent reading do engage the IFG (Assodollahi, Meinzer, Flaisch, Obleser, \& Rockstroh, 2009; Berl, Balsamo, Xu, Moore, Weinstein, Conry, et al., 2005; Chu, Lin, Chou, Tsai, Kuo, \& Jaaskelainen, 2013; Joubert, Beauregard, Walter, Bourgouin, Beaudoin, Leroux, et al., 2004; Stasenko, Hays, Wierenga, Gollen, 2020), our task involved the generation of silent narratives, not reading. Similarly, the striatum is sensitive to prediction error, but predictive processes involve other brain regions beyond the striatum, including the orbitofrontal cortex (OFC; Tanaka, Samejima, Okada, Ueda, Okamoto, Tamawaki et al., 2006). In addition, it seems plausible that the present method and approach might simply not have been sensitive enough to detect this seemingly extremely subtle semantic difference via BOLD activation in the IFG.

Finally, our visual complexity manipulation can also be interpreted as a 'humanness' manipulation, such that the more visual complex shapes appeared more human. This interpretation does not invalidate our conclusions, and future research can further tease visual complexity from perceived humanness.

\section{Implications}

Our results suggest that the valence of behaviour matters for anthropomorphism. The persistence of a negativity bias during explanation suggests that as human beings, we prioritise understanding negative behaviour. However, given the previous findings in the literature demonstrating that negative behaviour leads to less anthropomorphism for more complex entities (cadavers, robots, avatars, and corporations), this priority may not extend to all agents. Further research is necessary to better understand how the complexity of the agent, and its degree of humanness, influences mental state attribution for negative behaviour. 
Moreover, our results suggest that all motives for anthropomorphism may not be equal. The motive for understanding may be privileged over belonging and effectance motives during anthropomorphism given that belonging did not affect explanations for the different valenced behaviours, but did interact with effectance motives indicated by the prediction results. This makes evolutionary sense, and suggests that cases where anthropomorphism is encouraged, such as when designing artificial intelligence or animations, would benefit if agents displayed negative behaviours.

The valence difference, however, was not as consistent for predictions, and showed a bias towards positive behaviours as visual complexity increased, consistent with the finding for more complex entities (Khamitov, et al., 2016), but switched to a bias for negative behaviours for less complex agents when people were not socially isolated. This complexity suggests that valence may be more context specific for the effectance and isolation motives. Moreover, our data suggests that both motives interact; a novel finding in the anthropomorphism literature.

\section{Future Directions}

These results suggest that effectance and understanding are relevant for anthropomorphism. However, understanding is conflated with our measure of anthropomorphism, so it is difficult to dissociate the motive from the act of anthropomorphising. It may not be the case that people consciously consider these social motives when anthropomorphising. More likely, these motives are activated by the agent, and anthropomorphism addresses these motives. An interesting future question surrounds whether self-enhancement and trusting motives may also be relevant for anthropomorphism. We argued in the introduction that such motives depend on a human target, and should be irrelevant for anthropomorphism when the perceiver maintains the belief that the agent is not human. However, the preponderance of humanised animals such as pets, artificial intelligence, and robots suggests that human beings may begin to consider these other two motives during anthropomorphism. Future studies can more directly tests these motives using a clean experimental 
manipulation akin to Heider and Simmel (1944) animations, particularly if the brain will be explored. Presumably the context will again matter, and it should be possible to produce effects with these motives under circumstances where the distinction between human and not is blurred. Another possible future direction surrounds dissociating anthropomorphism to the moral agent and the moral patient in valenced behaviour situations. Our current analyses did not differentiate anthropomorphism to the two entities in our videos, but it is possible that the amount of anthropomorphism to each differed. Such a notion is consistent with the literature on anthropomorphism and moral behaviour (Swiderska \& Kuster, 2018; Tanibe, et al., 2017; Ward et al., 2013). Future research can use the word ratio measure that we employ to dissociate anthropomorphism to the moral agent and patient.

In closing, our studies build on the work of Cacioppo and colleagues, demonstrating nuances between social motives and valenced behaviour when anthropomorphism non-random motion of geometric shapes. We used brain imaging, guided by social psychological theory, to provide converging evidence for behavioural data, consistent with the approach to social neuroscience research advocated by Cacioppo and colleagues, resulting in this additional contribution to the literature. Thus, the legacy of Cacioppo's work lives on in social neuroscience and has implications as anthropomorphism of non-human entities becomes more common-place in modern, technologically driven societies. 


\section{References}

Andrews, K. (2009). Understanding norms without a theory of mind. Inquiry, 52(5), 433-448.

Andrews, K. (2012). Do Apes Read Minds? Toward a new folk psychology. MIT Press, Cambridge: MA.

Amodio, D. M., \& Frith, C. D. (2006). Meeting of minds: The medial frontal cortex and social cognition. Nature Reviews Neuroscience, 7(4), 268.

Assadollahi, R., Meinzer, M., Flaisch, T., Obleser, J., \& Rockstroh, B. (2009). The representation of the verb's argument structure as disclosed by fMRI. BMC Neuroscience, 10(1), 3.

Baumeister, R. F., \& Newman, L. S. (1994). How stories make sense of personal experiences: Motives that shape autobiographical narratives. Personality and Social Psychology Bulletin, 20(6), 676-690.

Baumeister, R. F., \& Leary, M. R. (1995). The need to belong: desire for interpersonal attachments as a fundamental human motivation. Psychological Bulletin, 117(3), 497-529.

Berl, M. M., Balsamo, L. M., Xu, B., Moore, E. N., Weinstein, S. L., Conry, J. A., Pearl, P. L., Sachs, B. C., Grandin, C. B., Frattali, C., Ritter, F. J., Sato, S., Theodore, W. H., \& Gaillard, W. D. (2005). Seizure focus affects regional language networks assessed by fMRI. Neurology, 65(10), 1604-1611.

Bowlby, J. (1969). Attachment and loss. Vol. 1: Attachment, New York: Basic Books.

Cacioppo, J. T., Berntson, G. G., Lorig, T. S., Norris, C. J., Rickett, E., \& Nusbaum, H. (2003). Just because you're imaging the brain doesn't mean you can stop using your head: a primer and set of first principles. Journal of Personality and Social Psychology, 85(4), 650.

Cacioppo, J. T., \& Gardner, W. L. (1999). Emotion. Annual review of psychology, 50(1), 191-214. 
Cacioppo, J. T., \& Hawkley, L. C. (2003). Social isolation and health, with an emphasis on underlying mechanisms. Perspectives in Biology and Medicine, 46, 39-52.

Carretié, L., Mercado, F., Tapia, M., \& Hinojosa, J. A. (2001). Emotion, attention, and the 'negativity bias', studied through event-related potentials. International Journal of Psychophysiology, 41(1), 75-85.

Chu, Y. H., Lin, F. H., Chou, Y. J., Tsai, K. W. K., Kuo, W. J., \& Jääskeläinen, I. P. (2013).

Effective cerebral connectivity during silent speech reading revealed by functional magnetic resonance imaging. PLoS One, 8(11).

Demoulin, S., Leyens, J. P., Paladino, M. P., Rodriguez-Torres, R., Rodriguez-Perez, A., \& Dovidio, J. (2004). Dimensions of "uniquely" and "non-uniquely" human emotions. Cognition and Emotion, 18(1), 71-96.

Dennett, D. C. (1989). The intentional stance. Cambridge, MA: MIT Press.

Epley, N., Akalis, S., Waytz, A., \& Cacioppo, J. T. (2008). Creating social connection through inferential reproduction: Loneliness and perceived agency in gadgets, gods, and greyhounds. Psychological Science, 19, 114-120.

Epley, N., Waytz, A., Akalis, S., \& Cacioppo, J. T. (2008). When we need a human:

Motivational determinants of anthropomorphism. Social Cognition, 26, 143-155.

Epley, N., Waytz, A., \& Cacioppo, J. T. (2007). On seeing human: A three-factor theory of anthropomorphism. Psychological Review, 114, 864-886.

Fiske, S. T. (2003). Five core social motives, plus or minus five. In S. Spencer, S. Fein, M. Zanna, \& J. Olson (Eds.), Motivated Social Perception: The Ontario Symposium, NJ: Lawrence Erlbaum.

Fiske, S. T., \& Taylor, S. E. (1991). Social Cognition, 2nd. NY: McGraw-Hill.

Fiske, S. T., \& Taylor, S. E. (2010). Social Cognition: From Brains to Culture, NY: McGraw-Hill. Gauthier, I., Behrmann, M., \& Tarr, M. J. (2004). Are Greebles like faces? Using the 
neuropsychological exception to test the rule. Neuropsychologia, 42(14), 1961-1970.

Gauthier, I., \& Tarr, M. J. (1997). Becoming a "Greeble” expert: Exploring mechanisms for face recognition. Vision Research, 37(12), 1673-1682.

Harmon-Jones, E., \& Devine, P. G. (2003). Introduction to the special section on social neuroscience: promise and caveats. Journal of Personality and Social Psychology, 85(4), 589.

Harris, L. T. (2017). Invisible mind: Flexible social cognition and dehumanization. MIT Press: Cambridge MA.

Harris, L. T., \& Fiske, S. T. (2008). The brooms in Fantasia: Neural correlates of anthropomorphizing objects. Social Cognition, 26(2), 210-223.

Harris, L., Lee, V. K., Thompson, E. H., \& Kranton, R. (2016). Exploring the generalization process from past behaviour to predicting future behaviour. Journal of Behavioural Decision Making, 29(4), 419-436.

Harris, L. T., Todorov, A., \& Fiske, S. T. (2005). Attributions on the brain: Neuro-imaging dispositional inferences, beyond theory of mind. Neuroimage, 28(4), 763-769.

Hawkley, L. C., \& Cacioppo, J. T. (2010). Loneliness matters: A theoretical and empirical review of consequences and mechanisms. Annals of Behavioural Medicine, 40, 218-227.

Hawkes, K. (2014). Primate sociality to human cooperation: Why us and not them? Human Nature, 25(1), 28-48.

Heberlein, A. S., \& Adolphs, R. (2004). Impaired spontaneous anthropomorphizing despite intact perception and social knowledge. Proceedings of the National Academy of Sciences, 101(19), 7487-7491. 
Heider, F., \& Simmel, M. (1944). An experimental study of apparent behaviour. The American Journal of Psychology, 57, 243-259.

Hrdy, S. (2009). Mothers and others: The evolutionary origins of mutual understanding. Cambridge: Harvard University Press.

Joubert, S., Beauregard, M., Walter, N., Bourgouin, P., Beaudoin, G., Leroux, J. M., Karama, S., \& Lecours, A. R. (2004). Neural correlates of lexical and sublexical processes in reading. Brain and Language, 89(1), 9-20.

Khamitov, M., Rotman, J. D., \& Piazza, J. (2016). Perceiving the agency of harmful agents: A test of dehumanization versus moral typecasting accounts. Cognition, 146, 33-47.

Kowalski, R. M., \& Leary, M. R. (1990). Strategic self-presentation and the avoidance of aversive events: Antecedents and consequences of self-enhancement and self-depreciation. Journal of Experimental Social Psychology, 26(4), 322-336.

Leary, M. R., Kelly, K. M., Cottrell, C. A., \& Schreindorfer, L. S. (2013). Construct validity of the need to belong scale: Mapping the nomological network. Journal of Personality Assessment, 95(6), 610-624.

Mars, R. B., Neubert, F. X., Noonan, M. P., Sallet, J., Toni, I., \& Rushworth, M. F. (2012).

On the relationship between the "default mode network" and the "social brain". Frontiers in Human Neuroscience, 6, 189.

Mogg, K., \& Bradley, B. P. (1998). A cognitive-motivational analysis of anxiety. Behaviour Research and Therapy, 36(9), 809-848.

Mogg, K., McNamara, J., Powys, M., Rawlinson, H., Seiffer, A., \& Bradley, B. P. (2000). Selective attention to threat: A test of two cognitive models of anxiety. Cognition \& Emotion, 14(3), 375-399.

Moran, J. M., Jolly, E., \& Mitchell, J. P. (2012). Social-cognitive deficits in normal aging. Journal of Neuroscience, 32(16), 5553-5561. 
Morewedge, C. K. (2009). Negativity bias in attribution of external agency. Journal of Experimental Psychology: General, 138(4), 535-545.

Ochsner, K. N., \& Lieberman, M. D. (2001). The emergence of social cognitive neuroscience. American Psychologist, 56(9), 717.

Oosterhof, N. N., \& Todorov, A. (2008). The functional basis of face evaluation. Proceedings of the National Academy of Sciences, 105(32), 11087-11092.

Paunonen, S. V. \& Jackson, D. N. (1985). Idiographic measurement strategies for personality and prediction: Some unredeemed promissory notes. Psychological Review, 92(4), 486.

Peeters, G., \& Czapinski, J. (1990). Positive- negative asymmetry in evaluations: the distinction between affective and informational negativity effects. European Review of Social Psychology, 1, 33-60.

Pervin, L. A. (1985). Personality: Current controversies, issues, and directions. Annual Review of Psychology, 36(1), 83-114.

Phillips, A. T., Wellman, H., \& Spelke, E. (2002). Infants' ability to connect gaze and emotional expression to intentional action. Cognition, 85, 53-78.

Puce, A., \& Perrett, D. (2003). Electrophysiology and brain imaging of biological motion. Philosophical Transactions of the Royal Society of London. Series B: Biological Sciences, $358(1431)$, 435-445.

Sanderman, R., Arrindell, W. A., \& Ranchor, A. V. (1991). Eysenck personality questionnaire (EPQ). Groningen: Noordelijk Centrum voor Gezondheidsvraagstukken.

Schultz, R. T., Grelotti, D. J., Klin, A., Kleinman, J., Van der Gaag, C., Marois, R., \& Skudlarski, 
P. (2003). The role of the fusiform face area in social cognition: implications for the pathobiology of autism. Philosophical Transactions of the Royal Society of London. Series B: Biological Sciences, 358(1430), 415-427.

Servos, P., Osu, R., Santi, A., \& Kawato, M. (2002). The neural substrates of biological motion perception: An fMRI study. Cerebral Cortex, 12(7), 772-782.

Stasenko, A., Hays, C., Wierenga, C. E., \& Gollan, T. H. (2020). Cognitive control regions are recruited in bilinguals' silent reading of mixed-language paragraphs. Brain and Language, 204, 104754.

Swiderska, A., \& Küster, D. (2018). Avatars in pain: Visible harm enhances mind perception in humans and robots. Perception, 47, 1139-1152. doi: 10.1177/0301006618809919

Tanaka, S. C., Samejima, K., Okada, G., Ueda, K., Okamoto, Y., Yamawaki, S., \& Doya, K. (2006). Brain mechanism of reward prediction under predictable and unpredictable environmental dynamics. Neural Networks, 19(8), 1233-1241.

Tanibe, T., Hashimoto, T., \& Karasawa, K. (2017). We perceive a mind in a robot when we help it. PLOS ONE, 12, e0180952.

Taylor, S.E. (1991). Asymmetrical effects of positive and negative events. The mobilisationminimisation hypothesis. Psychological Bulletin, 110, 67-85.

Tomasello, M., \& Gonzalez-Cabrera, I. (2017). The role of ontogeny in the evolution of human cooperation. Human Nature, 28(3), 274-288.

Tomasello, M., Melis, A. P., Tennie, C., Wyman, E., \& Herrmann, E. (2012). Two key steps in the evolution of cooperation: The interdependence hypothesis. Current Anthropology, 53(6), $673-692$.

Trevarthen, C. (1979). Communication and co-operation in early infancy: A description of primary intersubjectivity. In: M. Bullowa (Ed.), Before Speech, Cambridge: Cambridge University Press, pp. 321-47. 
Twenge, J. M., Baumeister, R. F., Tice, D. M., \& Stucke, T. S. (2001). If you can't join them, beat them: effects of social exclusion on aggressive behaviour. Journal of Personality and Social Psychology, 81(6), 1058.

Vaina, L. M., Solomon, J., Chowdhury, S., Sinha, P., \& Belliveau, J. W. (2001). Functional neuroanatomy of biological motion perception in humans. Proceedings of the National Academy of Sciences, 98(20), 11656-11661.

Van Overwalle, F. (2009). Social cognition and the brain: A meta-analysis. Human Brain Mapping, 30(3), 829-858.

Ward, A. F., Olsen, A. S., \& Wegner, D. M. (2013). The harm-made mind: Observing victimization augments attribution of minds to vegetative patients, robots, and the dead. Psychological Science, 24, 1437-1445.

Waytz, A., Cacioppo, J. T., \& Epley, N. (2010). Who sees human? The stability and importance of individual differences in anthropomorphism. Perspectives on Psychological Science, 5, 219-232.

Waytz, A., Morewedge, C. K., Epley, N., Monteleone, G., Gao, J.-H., \& Cacioppo, J. T. (2010). Making sense by making sentient: Effectance motivation increases anthropomorphism. Journal of Personality and Social Psychology, 99, 410-435. 


\section{Acknowledgements}

We would like to thank Beatrice Capestany and Alyssa Fowers for building the animations, and Beatrice Capestany for collecting and assisting with analyzing the fMRI data. This work was funded by start-up funds to the first author by Duke University, and an award to the second author by Leiden University. The second study comprised the second author's MSc thesis. 
Table 1

Non-random versus random movement

\begin{tabular}{ccccc}
\hline Brain Region & $\begin{array}{c}\text { Talairach } \\
\text { Coordinates } \\
(x, y, z)\end{array}$ & Voxels & Z-value & P-value \\
\hline $\begin{array}{c}\text { Right Precentral Gyrus } \\
\text { (BA 4) }\end{array}$ & $46,-12,43$ & 29 & 5.21 & $1.23 \mathrm{E}-04$ \\
$\begin{array}{c}\text { Right Parietal Lobe } \\
\text { (BA 40) }\end{array}$ & $37,-44,34$ & 96 & 5.16 & $1.29 \mathrm{E}-04$ \\
\hline
\end{tabular}

Note: Data represents the results of a whole brain contrast between non-random and random movement of agents in the videos, collapsed across the other independent variables. Voxels counts are taken at $3 \times 3 \times 3 \mathrm{~mm}^{3}$ resolution. All statistics are uncorrected. 
Table 2

Harming behaviour versus helping behaviour

\begin{tabular}{ccccc}
\hline Brain Region & $\begin{array}{c}\text { Talairach } \\
\text { Coordinat } \\
\text { es }(x, y, z)\end{array}$ & Voxels & Z-value & P-value \\
\hline $\begin{array}{c}\text { Right Anterior Cingulate } \\
\text { Cortex (BA 33) }\end{array}$ & $4,19,20$ & 21 & 5.44 & $7.10 \mathrm{E}-05$ \\
$\begin{array}{c}\text { Right Anterior Cingulate } \\
\text { Cortex (BA 33) }\end{array}$ & $7,19,16$ & 14 & 5.36 & $8.00 \mathrm{E}-05$ \\
$\begin{array}{c}\text { Right Anterior Cingulate } \\
\text { Cortex (BA 24) }\end{array}$ & $3,30,8$ & 11 & & \\
& & & 5.55 & \\
& & & & \\
Left Cerebellar Tonsil & $-23,-55,-$ & 86 & 5.62 & $5.40 \mathrm{E}-05$ \\
& 36 & 12 & 5.37 & $7.80 \mathrm{E}-05$ \\
\hline
\end{tabular}

Note: Data represents the results of a whole brain contrast between harming and helping behaviours of agents in the videos, collapsed across the other independent variables. Voxels counts are taken at $3 \times 3 \times 3 \mathrm{~mm}^{3}$ resolution. All statistics are uncorrected. 
Table 3

CG faces versus greebles and geometric shapes deviant cell contrast analysis

\begin{tabular}{ccccc}
\hline Brain Region & $\begin{array}{c}\text { Talairach } \\
\text { Coordinate } \\
\mathrm{s}(x, y, z)\end{array}$ & Voxels & Z-value & P-value \\
\hline $\begin{array}{c}\text { Left Superior Temporal } \\
\text { Gyrus (BA 10) }\end{array}$ & $-4,66,23$ & 11 & 4.29 & $6.72 \mathrm{E}-04$ \\
\hline
\end{tabular}

Note: Data represents the results of a whole brain contrast between CG faces and the other two types of agents in the videos, collapsed across the other independent variables. Voxels counts are taken at $3 \times 3 \times 3 \mathrm{~mm}^{3}$ resolution. All statistics are uncorrected. 
Table 4

Greebles versus $C G$ faces and geometric shapes deviant cell contrasts analysis

\begin{tabular}{ccccc}
\hline Brain Region & $\begin{array}{c}\text { Talairarch } \\
\text { Coordinates } \\
(x, y, z)\end{array}$ & Voxels & Z-value & P-value \\
\hline $\begin{array}{c}\text { Left Fusiform Gyrus } \\
\text { (BA 20) }\end{array}$ & $-48,-4,-24$ & 74 & -4.5 & $4.61 \mathrm{E}-04$ \\
$\begin{array}{c}\text { Left Inferior Temporal } \\
\text { Gyrus (BA 20) }\end{array}$ & $-40,-9,-32$ & 28 & -4.46 & $4.91 \mathrm{E}-04$ \\
$\begin{array}{c}\text { Left Superior Temporal } \\
\text { Gyrus (BA 38) }\end{array}$ & $-31,10,-31$ & 58 & -4.38 & $5.53 \mathrm{E}-04$ \\
& & & & \\
\hline
\end{tabular}

Note: Data represents the results of a whole brain contrast between greebles and the other two types of agents in the videos, collapsed across the other independent variables. Voxels counts are taken at $3 \times 3 \times 3 \mathrm{~mm}^{3}$ resolution. All statistics are uncorrected. 
Table 5

Geometric shapes versus CG faces and greebles deviant cell contrast analysis

\begin{tabular}{ccccc}
\hline Brain Region & $\begin{array}{c}\text { Talairach } \\
\text { Coordinates } \\
(x, y, z)\end{array}$ & Voxels & Z-value & P-value \\
\hline $\begin{array}{c}\text { Right Rectal Gyrus } \\
\text { (BA11) } \\
\text { Right Tonsil }\end{array}$ & $4,36,-20$ & 13 & 3.96 & $1.32 \mathrm{E}-03$ \\
\hline
\end{tabular}

Note: Data represents the results of a whole brain contrast between geometric shapes and the other two types of agents in the videos, collapsed across the other independent variables. Voxels counts are taken at $3 \times 3 \times 3 \mathrm{~mm}^{3}$ resolution. All statistics are uncorrected. 
Table 6

Mean Word Usage

\begin{tabular}{ccc}
\hline Behaviour & $\begin{array}{c}\text { Mental State } \\
\text { Word Mean }\end{array}$ & $\begin{array}{c}\text { Human Word } \\
\text { Mean }\end{array}$ \\
\hline $\begin{array}{c}\text { Harming } \\
\text { Behaviour }\end{array}$ & 5.02 & $4.17 \mathrm{E}-06$ \\
$\begin{array}{c}\text { Helping } \\
\text { Behaviour }\end{array}$ & 3.48 & $2.51 \mathrm{E}-01$ \\
Random Motion & 0.08 & $1.33 \mathrm{E}-04$ \\
\hline
\end{tabular}


Table 7

Weighted Analyses for CG Faces

\begin{tabular}{|c|c|c|c|c|}
\hline Brain Region & $\begin{array}{c}\text { Talairach } \\
\text { Coordinates }(x, y, \\
z)\end{array}$ & Voxels & Z-value & P-value \\
\hline $\begin{array}{l}\text { Left Superior Parietal } \\
\text { Lobule (BA7) }\end{array}$ & $-25,-64,52$ & 5868 & 4.39 & $7.82 \mathrm{E}-04$ \\
\hline Right Precuneus (BA 7) & $21,-70,53$ & 2868 & 4.29 & $3 \mathrm{E}-04$ \\
\hline $\begin{array}{l}\text { Left Inferior Occipital } \\
\text { Gyrus (BA 18) }\end{array}$ & $-33,-83,-14$ & 13365 & 157 & $.47 \mathrm{E}-04$ \\
\hline $\begin{array}{l}\text { Right Middle Occipital } \\
\text { Gyrus (BA 18) }\end{array}$ & $35,-79,-8$ & 12940 & & $7.49 \mathrm{E}-04$ \\
\hline $\begin{array}{c}\text { Left Precentral Gyrus (BA } \\
6 \text { ) }\end{array}$ & $-25,-14,53$ & & 4.53 & $6.91 \mathrm{E}-04$ \\
\hline $\begin{array}{l}\text { Right Precentral Gyrus } \\
\text { (BA 6) }\end{array}$ & $23,-15,53$ & & 4.29 & $8.72 \mathrm{E}-04$ \\
\hline $\begin{array}{l}\text { Left Inferior Parietal } \\
\text { Lobule (BA 40) }\end{array}$ & & 2175 & 4.59 & $6.68 \mathrm{E}-04$ \\
\hline $\begin{array}{c}\text { Left Temporal Lobe (BA } \\
21)\end{array}$ & & 4328 & -4.70 & $6.60 \mathrm{E}-04$ \\
\hline $\begin{array}{l}\text { Right Middle Temporal } \\
\text { Gyrus (BA 39) }\end{array}$ & & 804 & -4.10 & $1.25 \mathrm{E}-03$ \\
\hline Right Insula (BA 13) & $43,-14,1$ & 5556 & -4.37 & 8.02E-04 \\
\hline $\begin{array}{l}\text { Left Anterior Cingulate } \\
\text { Cortex (BA 31) }\end{array}$ & $-1,-40,41$ & 234 & -3.86 & $1.59 \mathrm{E}-03$ \\
\hline Left Cerebellum, Culmen & $-18,-45,-16$ & 821 & -3.93 & $1.41 \mathrm{E}-03$ \\
\hline
\end{tabular}

Note: Data represents the results of a whole brain contrast using weighted means just for CG faces. Brain regions with -ve statistical values are inversely correlated. Voxels counts are taken at $1 \times 1 \times$ $1 \mathrm{~mm}$ resolution. All statistics are uncorrected. 
Table 8

Weighted Analyses for Greebles

\begin{tabular}{|c|c|c|c|c|}
\hline Brain Region & $\begin{array}{c}\text { Talairach } \\
\text { Coordinates }(x, \\
y, z)\end{array}$ & Voxels & Z-value & P-value \\
\hline Left Fusiform Gyrus (BA 19) & $-35,-80,-13$ & 10170 & 4.29 & $8.89 \mathrm{E}-04$ \\
\hline $\begin{array}{l}\text { Right Inferior Occipital } \\
\text { Gyrus (BA 17) }\end{array}$ & $23,-92,-9$ & 4471 & 4.15 & J \\
\hline $\begin{array}{c}\text { Right Inferior Occipital } \\
\text { Gyrus (BA 19) }\end{array}$ & $44,-70,-5$ & 5910 & 4.44 & $8.14 \mathrm{E}-04$ \\
\hline Left Precentral Gyrus (BA 6) & $-25,-14,54$ & 2729 & & 5.89E-04 \\
\hline $\begin{array}{l}\text { Right Middle Frontal Gyrus } \\
\text { (BA 6) }\end{array}$ & $24,-15,54$ & & 4.50 & 7.58E-04 \\
\hline Left Precuneus (BA 7) & $-24,-67,51$ & 7070 & 4.42 & $7.84 \mathrm{E}-04$ \\
\hline Right Precuneus (BA 7) & $19,-74,54$ & 4532 & 4.11 & $1.06 \mathrm{E}-03$ \\
\hline $\begin{array}{l}\text { Left Inferior Parietal Lobule } \\
\text { (BA 40) }\end{array}$ & & 1962 & 4.33 & $9.02 \mathrm{E}-04$ \\
\hline $\begin{array}{l}\text { Left Superior Frontal Gyrus } \\
\text { (BA 9) }\end{array}$ & & 2428 & -4.14 & $1.08 \mathrm{E}-03$ \\
\hline $\begin{array}{l}\text { Right Middle Frontal Gyru } \\
\text { (BA 9) }\end{array}$ & 36 & 3108 & -4.20 & 9.97E-04 \\
\hline $\begin{array}{l}\text { Right Anterior Cingulate } \\
\text { Cortex (BA 32) }\end{array}$ & $3,16,31$ & 1916 & -3.90 & $1.50 \mathrm{E}-03$ \\
\hline $\begin{array}{c}\text { Right Anterior Cingulate } \\
\text { Cortex (BA 24) }\end{array}$ & $3,-1,40$ & 271 & -3.83 & $1.68 \mathrm{E}-03$ \\
\hline Left Temporal Lobe (BA 21) & $-42,-8,-10$ & 3965 & -4.33 & $9.10 \mathrm{E}-04$ \\
\hline $\begin{array}{c}\text { Right Superior Temporal } \\
\text { Gyrus (BA 38) }\end{array}$ & $36,6,-17$ & 480 & -4.06 & $1.18 \mathrm{E}-03$ \\
\hline $\begin{array}{c}\text { Right Angular Gyrus (BA } \\
39 \text { ) }\end{array}$ & $50,-64,35$ & 729 & -3.85 & $1.61 \mathrm{E}-03$ \\
\hline
\end{tabular}

Note: Data represents the results of a whole brain contrast using weighted means just for greebles.

Brain regions with -ve statistical values are inversely correlated. Voxels counts are taken at $1 \times 1 \times$ $1 \mathrm{~mm}$ resolution. All statistics are uncorrected. 
Table 9

Weighted Analysis for Geometric Shapes

\begin{tabular}{|c|c|c|c|c|}
\hline Brain Region & $\begin{array}{c}\text { Talairach } \\
\text { Coordinates }(x, \\
y, z)\end{array}$ & Voxels & Z-value & P-value \\
\hline $\begin{array}{l}\text { Left Superior Parietal Lobule } \\
\text { (BA 7) }\end{array}$ & $-23,-71,56$ & 5822 & 3.82 & $2.95 \mathrm{E}-03$ \\
\hline Right Precuneus (BA 7) & $19,-76,54$ & 5106 & 3.57 & E-03 \\
\hline Left Precentral Gyrus (BA 6) & $-26,-15,52$ & 1912 & 4.19 & $2.42 \mathrm{E}-03$ \\
\hline $\begin{array}{c}\text { Right Precentral Gyrus (BA } \\
6 \text { ) }\end{array}$ & $24,-17,53$ & 571 & 3.39 & $4.71 \mathrm{E}-03$ \\
\hline $\begin{array}{l}\text { Left Inferior Occipital Gyrus } \\
\text { (BA 19) }\end{array}$ & $-45,-71,-5$ & 2 & 4 & $3.27 \mathrm{E}-03$ \\
\hline $\begin{array}{l}\text { Right Inferior Occipital } \\
\text { Gyrus (BA 19) }\end{array}$ & $44,-70,-4$ & & 3.79 & $3.29 \mathrm{E}-03$ \\
\hline $\begin{array}{l}\text { Left Inferior Parietal Lobule } \\
\text { (BA 40) }\end{array}$ & - & & 3.73 & 3.32E-03 \\
\hline $\begin{array}{l}\text { Left Inferior Parietal Lobule } \\
\text { (BA 40) }\end{array}$ & & 533 & 3.66 & $3.65 \mathrm{E}-03$ \\
\hline $\begin{array}{l}\text { Left Middle Temporal Gyrus } \\
\text { (BA 21) }\end{array}$ & & 443 & -3.14 & $6.94 \mathrm{E}-03$ \\
\hline
\end{tabular}

Note: Data represents the results of a whole brain contrast using weighted means just for geometric shapes. Brain regions with -ve statistical values are inversely correlated. Voxels counts are taken at $1 \times 1 \times 1 \mathrm{~mm}$ resolution. All statistics are uncorrected. 
Table 10

Weighted Analysis for All Agents

\begin{tabular}{|c|c|c|c|c|}
\hline Brain Region & $\begin{array}{c}\text { Talairach } \\
\text { Coordinates }(x, \\
y, z)\end{array}$ & Voxels & Z-value & P-value \\
\hline Left Precentral Gyrus (BA 6) & $-26,-14,53$ & 4054 & 4.31 & $1.90 \mathrm{E}-03$ \\
\hline $\begin{array}{l}\text { Right Middle Frontal Gyrus } \\
\text { (BA 6) }\end{array}$ & $24,-15,53$ & 1739 & 3.97 & \\
\hline Left Precuneus (BA 7) & $-24,-67,51$ & 10084 & 4.09 & $2.00 \mathrm{E}-03$ \\
\hline Right Precuneus (BA 7) & $19,-74,54$ & 6883 & & $2.42 \mathrm{E}-03$ \\
\hline $\begin{array}{l}\text { Left Inferior Parietal Lobule } \\
\text { (BA 40) }\end{array}$ & $-57,-25,33$ & 3942 & 00 & $2.46 \mathrm{E}-03$ \\
\hline $\begin{array}{l}\text { Right Postcentral Gyrus (BA } \\
\text { 5) }\end{array}$ & $22,-40,68$ & & -3.42 & 4.19E-03 \\
\hline $\begin{array}{l}\text { Left Postcentral Gyrus (BA } \\
5 \text { ) }\end{array}$ & - & & -3.45 & $4.20 \mathrm{E}-03$ \\
\hline $\begin{array}{c}\text { Right Angular Gyrus (BA } \\
39 \text { ) }\end{array}$ & & 6647 & -3.67 & $3.15 \mathrm{E}-03$ \\
\hline $\begin{array}{l}\text { Left Superior Temporal } \\
\text { Gyrus (BA 39) }\end{array}$ & & 2367 & -3.58 & $3.50 \mathrm{E}-03$ \\
\hline Left Middle Frontal Gyrus & $-26,37,37$ & 5404 & -3.34 & 4.75E-03 \\
\hline
\end{tabular}

Note: Data represents the results of a whole brain contrast using weighted means for all agents.

Brain regions with - ve statistical values are inversely correlated. Voxels counts are taken at $1 \times 1 \times$ $1 \mathrm{~mm}$ resolution. All statistics are uncorrected. 


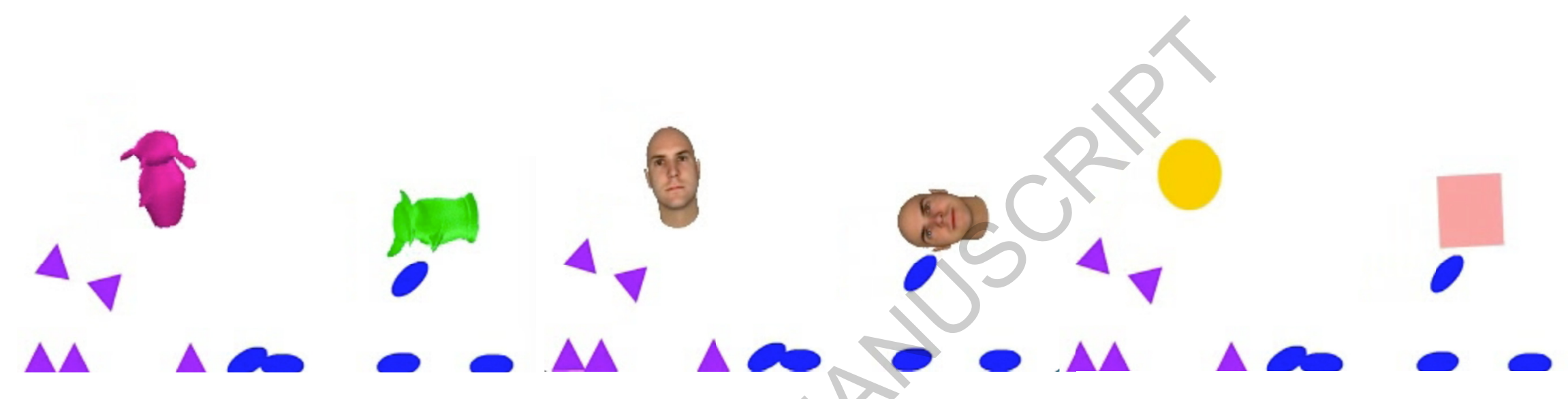

Figure 1: Stimuli of Agents in Motion. Screenshots of the three types of agents used in study one. Here, the agents were engaged in sorting behaviour, separating the purple triangles from the blue ovals. 
a)

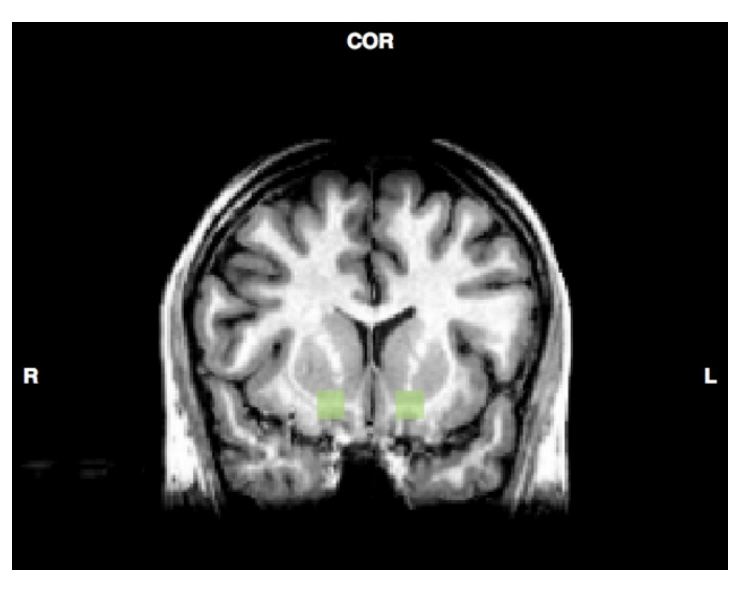

(b) Right Striatum

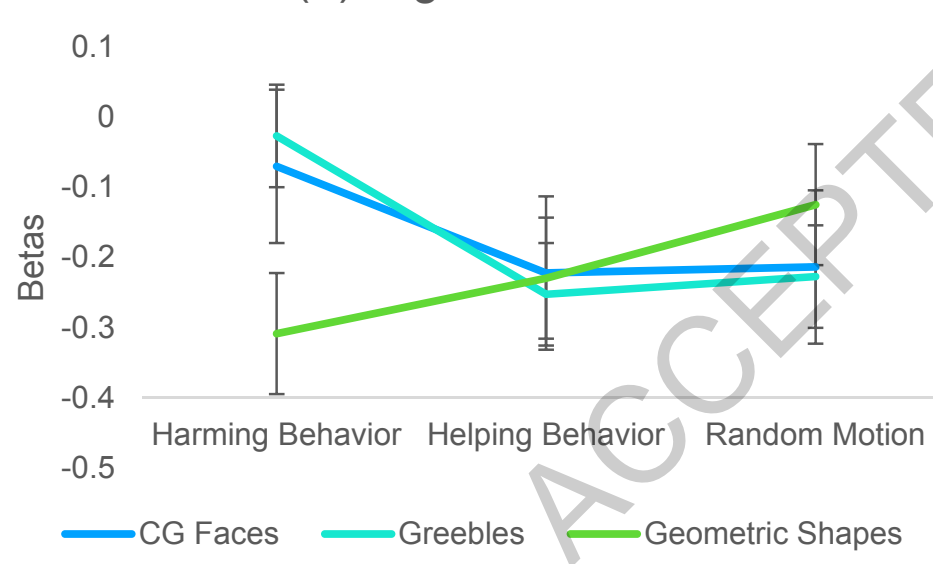

(c) Left Striatum

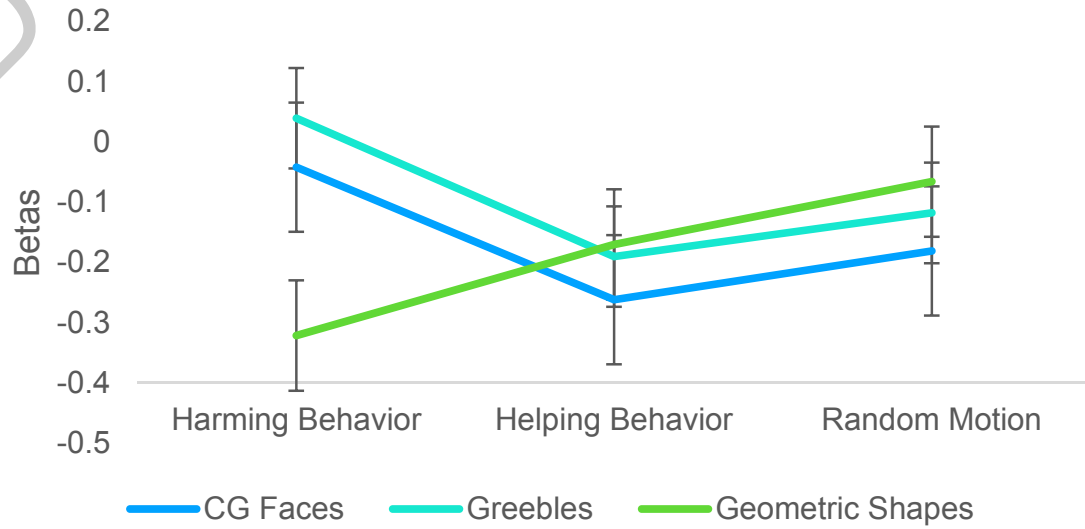

Figure 2: Striatum ROI Brain Activity. (a) The location of left and right striatum ROIs centered on the putamen at $x=(-) 14, y=10, z=-10$. (b) Extracted betas from the right putamen. Error bars show standard error of the mean. (c) Extracted betas from the left putamen. 


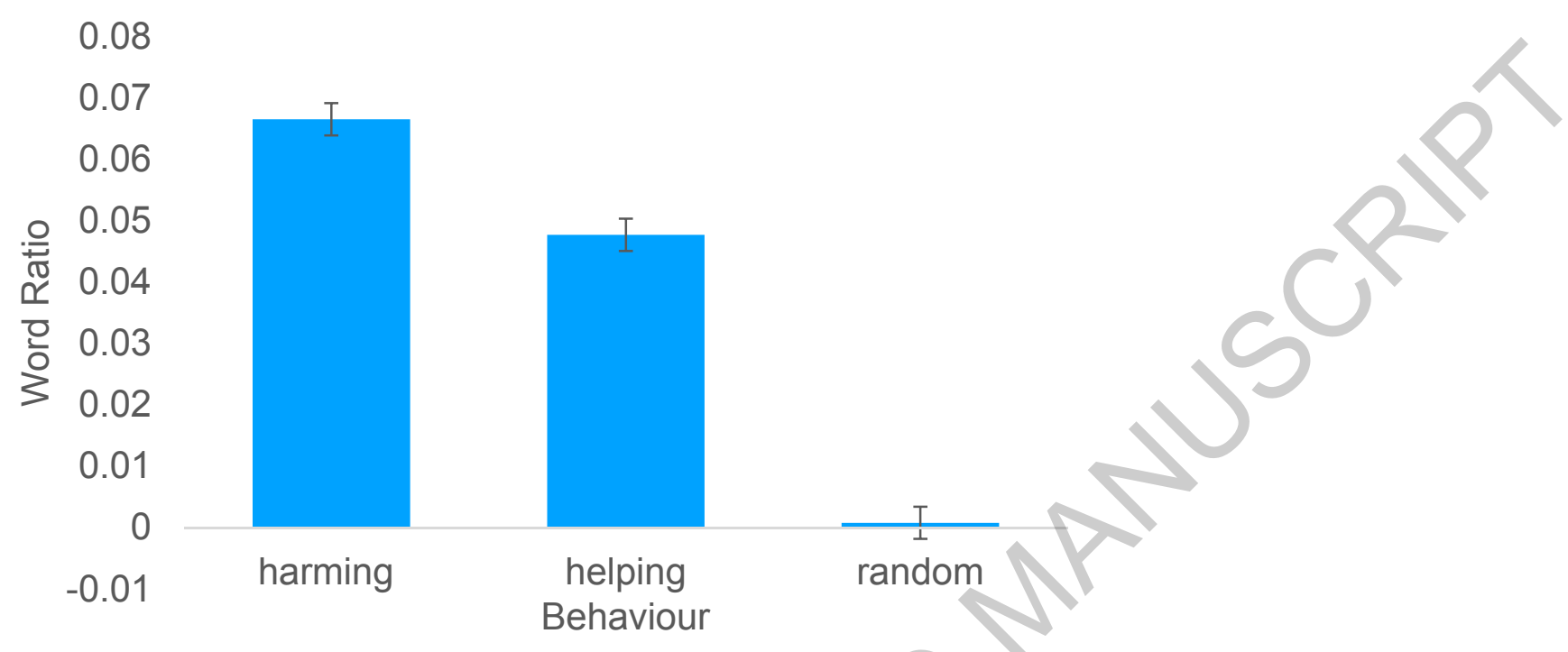

Figure 3: Anthropomorphic Word Use During Narrations. Means capture the amount of anthropomorphic words relative to the total number of words used when participants were relaying a narrative that explained the observed behaviour of the agents. Error bars represent the standard error of the mean. 
(a) Relevant to Observed Behaviour

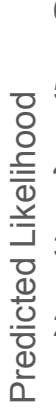

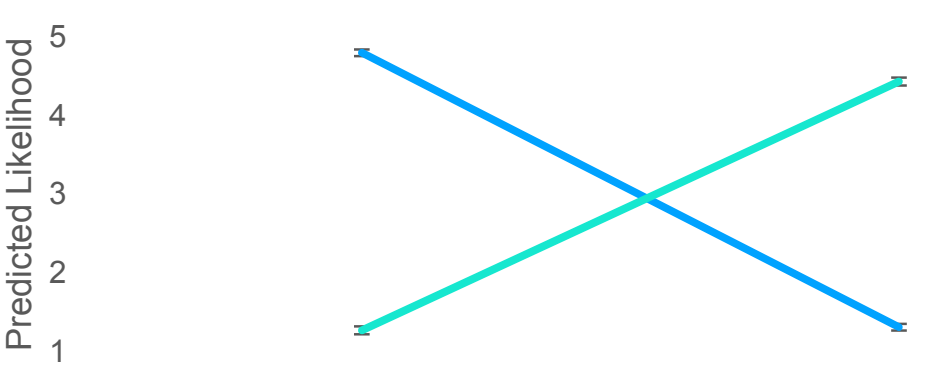

0

observed help

observed harm

future help —uture harm

(b) Irrelevant to Observed Behaviour

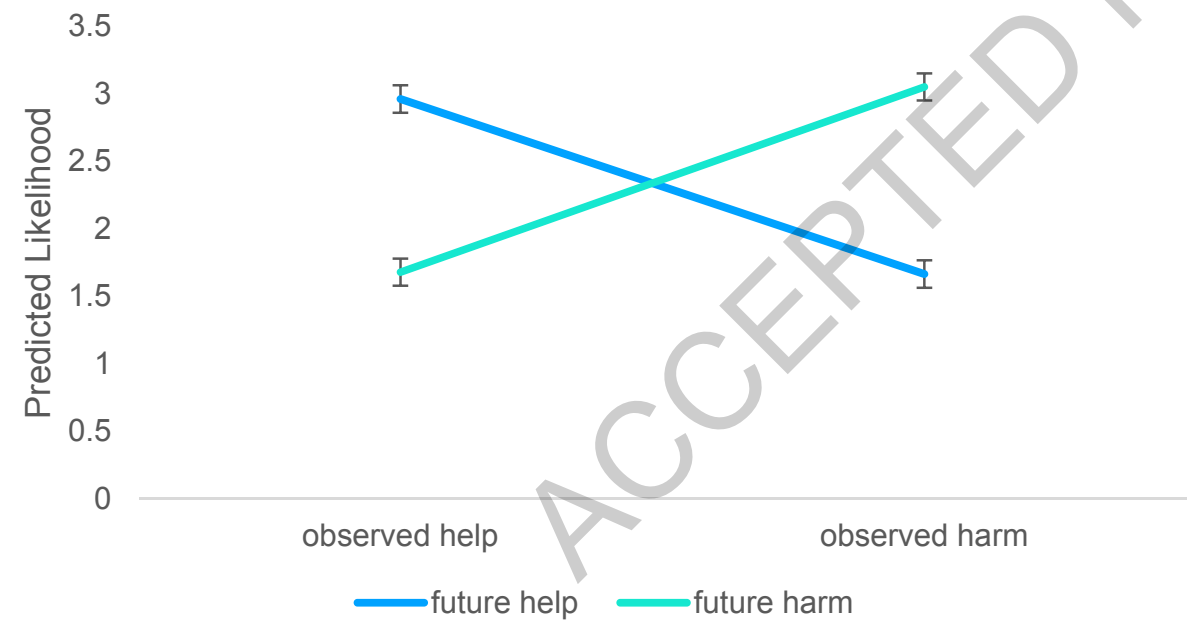

Figure 4: Predicted Likelihood of Agent Future Behaviour. Means capture the likelihood of an agent engaging in similar behaviour in the future for (a) relevant and (b) irrelevant behaviours. Error bars represent the standard error of the mean. 
(a) Relevant to Observed Behaviour

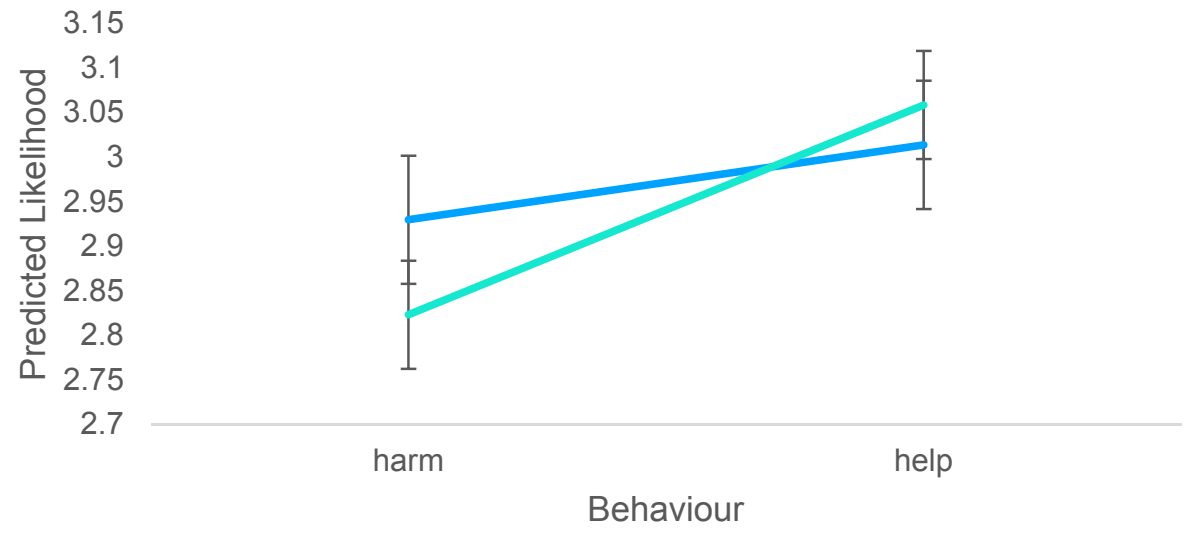

Ionely not lonely

(b) Irrelevant to Observed Behaviour

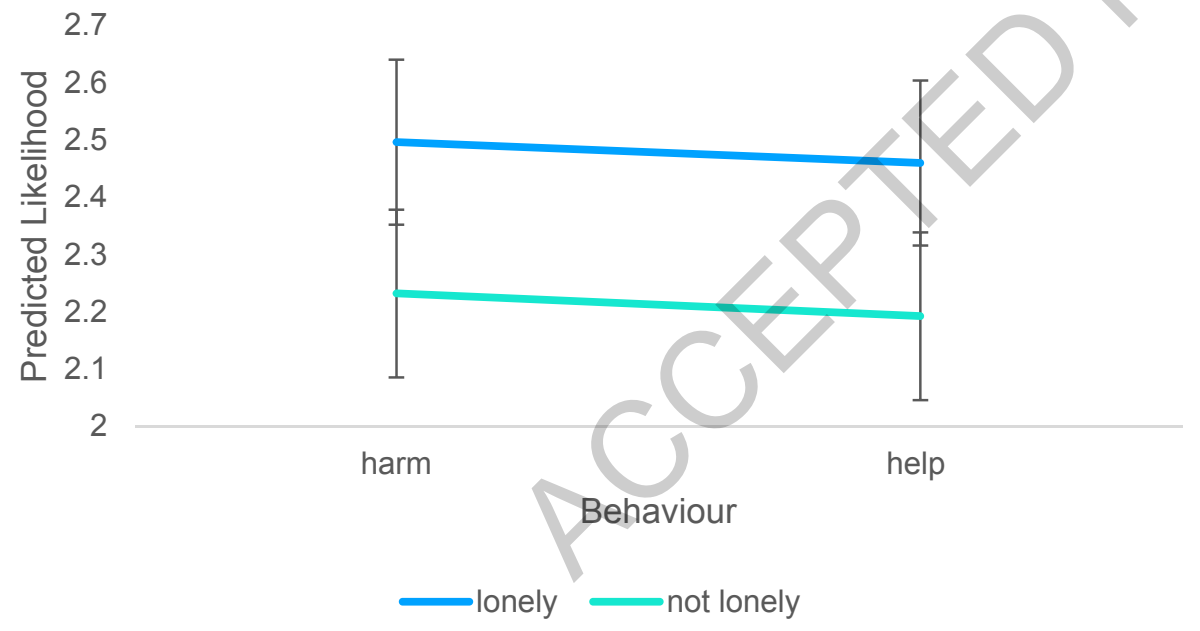

Figure 5: Predicted Likelihood of Agent Future Behaviour. Means capture the likelihood of an agent engaging in similar behaviour in the future for participants in the (a) lonely and (b) not lonely conditions. Error bars represent the standard error of the mean. 